\title{
A Numerical Algorithm for the Analysis of the Thermal Stress-Stain State of a Rod
}

\author{
Kanat Amirtayev \\ A Yesevi International Kazakh, Turkish University, Turkestan, Republic of Kazakhstan
}

Copyright $(2018$ by authors, all rights reserved. Authors agree that this article remains permanently open access under the terms of the Creative Commons Attribution License 4.0 International License

\begin{abstract}
A universal algorithm for solving applied tasks of thermo elastic state of a partially heat insulated rod of limited length, in the presence of axial force, temperature, heat flow and heat exchange, was developed. The corresponding numerical calculation of efforts of the rod partially thermally insulated and clamped by two ends, in the presence of heat flow was elaborated. The numerical algorithm allowed calculate the lengthening value of the partially thermally insulated rod or the compressive stress and strain in the rods of limited length with the heat flow, the heat exchange, heat insulation and the axial tensile force.
\end{abstract}

Keywords Universal Algorithm, Thermo Elastic State, Limited Length; Axial Force, Heat Flow, Efforts of the Rod, Axial Tensile Force

\section{Introduction}

Construction of numerical algorithms and complex of programs, as well as the solution of the task of the steady thermal elastic state of a partially isolated heat rod while the simultaneous effects of axial force, temperature and heat flow represent the appropriate mathematical and computational difficulties. In view of the importance of ensuring stable work of construction elements, while the simultaneous thermal and mechanical action, we are really convinced that the development of universal computing algorithms of established processes, of the field temperature distribution, of elastic displacements and thermo elastic condition of construction elements with mechanical forces, heat flow, partial insulation and heat exchange is the actual problem of modern numerical methods.

With simultaneous consideration of the above factors, the analytical solution of the steady thermo elastic compression and stretching of the rods becomes very complicated. In this connection, the need naturally arises to develop appropriate universal computational algorithms oriented to modern computer facilities and object-oriented high-level programming languages that allow one to investigate the thermo elastic state of partially insulated one-dimensional structural elements, in the presence of heat exchange with the environment, the temperature field, thermal and axial tensile forces.

On the basis of the energy principles and finite element method with quadratic elements, the universal numerical algorithm for solving applied tasks of thermo elastic state of a partially heat insulated rod of limited length, in the presence of axial force, temperature, heat flow and heat exchange, was developed.

The field regularities of distribution of the temperature, displacement, deformation and strain along the length of the rod, depending on the area of the lateral heat-isolated surface, on the applied temperature, heat flow, heat exchange and heat exchange coefficients with the surrounding parts of the lateral surface, were revealed.

\section{Calculation Scheme of the Task}

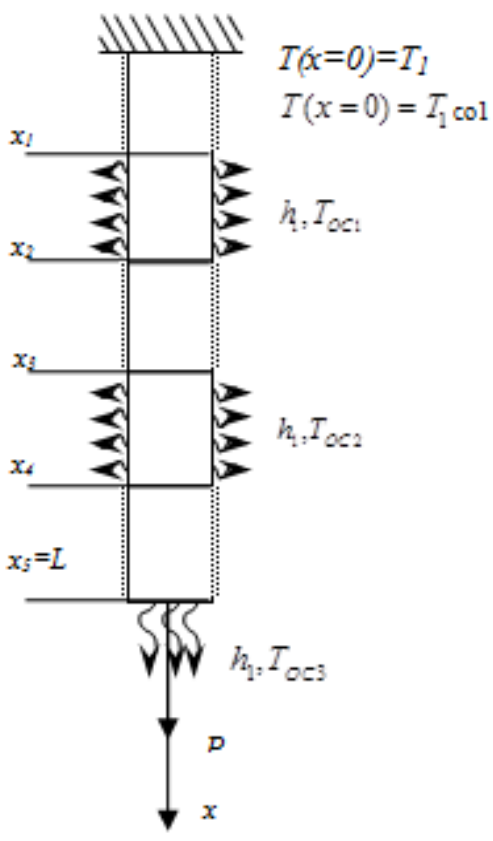

Figure 1. Calculation scheme of the task 
Earlier the authors made the numerical study of lengthening of partially heat-isolated rod in the presence of a heat sources and tensile strength is given. The numerical study with the different source data was conducted [1].

To do it, the rod $L$ with length will be to discrete quadratic finite elements with three nodes.

Then, for the final elements in the heat isolated lateral surface parts, the view o the functional, expressing conservation and change of the total thermal energy is as follows

$$
I_{i}=\int_{V_{i}} \frac{K_{x x}}{2}\left(\frac{\partial T}{\partial x}\right)^{2} d V
$$

For the finite element heat isolated by the lateral surface, the functional type is as follows

$$
I_{n}=\int_{V_{n}} \frac{K_{x x}}{2}\left(\frac{\partial T}{\partial x}\right)^{2} d V+\int_{S_{s s}^{s}} \frac{h_{3}}{2}\left(T-T_{O C 3}\right)^{2} d S
$$

On the lateral surface $x_{1} \leq x \leq x_{2}$ of the rod, the heat exchange with the environment takes place.

$$
I_{j}=\int_{V_{j}} \frac{K_{x x}}{2}\left(\frac{\partial T}{\partial x}\right)^{2} d V+\int_{S_{s l s}^{j}} \frac{h_{1}}{2}\left(T-T_{o c 1}\right)^{2} d S
$$

On the lateral surface $x_{3} \leq x \leq x_{4}$ of the rod, the heat exchange with the environment takes place as well.

$$
I_{k}=\int_{V_{k}} \frac{K_{x x}}{2}\left(\frac{\partial T}{\partial x}\right)^{2} d V+\int_{S_{s l s}^{k}} \frac{h_{2}}{2}\left(T-T_{O C 2}\right)^{2} d S
$$

Then, for the rod in general, the expression of the corresponding functional is as follows

$$
I=I_{i}+I_{j}+I_{k}+I_{n} \text {. }
$$

The influence of temperature and tensile strength on the lengthening of the rod was analyzed [1].

Moreover, the lengthening of considered rod is affected the by heat transfer coefficient $h,\left(\mathrm{Vt} / \mathrm{CM}^{2} \cdot{ }^{\circ} \mathrm{C}\right)$ between the rod material and the cross-sectional area of the clamped rod ends [2].

\section{The Payment Scheme}

The numerical study of thermal strain deformed of partially heat isolated and clamped by two rod ends of limited length in the presence of different heat sources was carried out [3].

The field of temperature distribution along the length of the rod, the law of distribution of elastic displacements, strain and stress components along the length of the rod was defined. For this, the length of the rod is divided into equal $n$-parts. Then the length of one side will be $l=L / n$. The number of nodes of the discrete elements will be $2 n+1$. The field of distribution of temperature and elastic displacement within each element is approximated by a quadratic curve passing through three points.

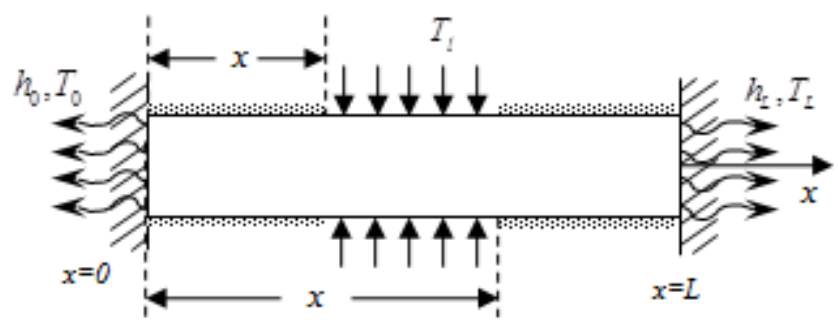

Figure 2. The payment scheme

$$
\left.\begin{array}{l}
T(x)=\varphi_{i}(x) T_{i}+\varphi_{j}(x) T_{j}+\varphi_{k}(x) T_{j} \\
u(x)=\varphi_{i}(x) u_{i}+\varphi_{j}(x) u_{j}+\varphi_{k}(x) u_{k}
\end{array}\right\}
$$

For the first element the form of the functional that expresses the full heat energy is as follows

$$
I_{1}=\frac{F K_{x x}}{2 l}\left[\begin{array}{l}
\frac{7}{3} T_{1}^{2}-\frac{16}{3} T_{1} T_{2}+\frac{2}{3} T_{1} T_{3}- \\
-\frac{16}{3} T_{2} T_{3}+\frac{16}{3} T_{2}^{2}+\frac{7}{3} T_{3}^{2}
\end{array}\right]+\frac{F h_{0}}{2}\left(T_{1}-T_{0}\right)^{2}
$$

And for all other elements of the portion $0 \leq x \leq x_{1}$ of the rod, the analogous functional form will be as follows

$I_{2 i}=\int_{V_{i}} \frac{K_{x x}}{2}\left(\frac{\partial T}{\partial x}\right)^{2} d V=\frac{F K_{x x}}{2 l}\left[\begin{array}{l}\frac{7}{3} T_{i}^{2}-\frac{16}{3} T_{i} T_{j}+\frac{2}{3} T_{i} T_{k}- \\ -\frac{16}{3} T_{j} T_{k}+\frac{16}{3} T_{j}^{2}+\frac{7}{3} T_{k}^{2}\end{array}\right]$

The last $n$ element was considered. The lateral surface of this element was thermally insulated. But through cross sectional area of the right end, which corresponds to the section $x=L$, a heat exchange with the environment takes place. Then this element is characterized by full expression of functional thermal energy has the following form

$$
\begin{aligned}
& I_{n}=\int_{v_{n}} \frac{K_{x x}}{2}\left(\frac{\partial T}{\partial x}\right)^{2} d V+\int_{s_{n+1}} \frac{h_{L}}{2}\left(T-T_{L}\right)^{2} d S= \\
& =\frac{F K_{x x}}{2 l}\left[\frac{7}{3} T_{n-1}^{2}-\frac{16}{3} T_{n-1} T_{n}+\right. \\
& \left.+\frac{2}{3} T_{n-1} T_{n+1}-\frac{16}{3} T_{n} T_{n+1}+\frac{16}{3} T_{n}^{2}+\frac{7}{3} T_{n+1}^{2}\right]+ \\
& +\frac{F h_{L}}{2}\left(T_{n+1}-T_{L}\right) .
\end{aligned}
$$

By minimizing, $I$ by $T_{i}$ we get the resolution system of algebraic equations regarding the given parameters, i.e.

$$
\frac{\partial I}{\partial T_{i}}=0
$$

Solving the resulting system of linear algebraic equations by Gauss method, we determine the nodal 
temperatures $T_{i}$.

Then we present the second part of the considered problem. For each quadratic finite element with the length $l_{1}$ the expression of the potential energy of elastic deformations, taking into account the available steady temperature field, is

$$
\Pi_{i}=\int_{V_{i k}} \frac{\sigma_{x} \varepsilon_{x}}{2} d V-\alpha E \int_{V_{i}} T(x) \varepsilon_{x} d V
$$

Within this element, the expression of the elastic component of deformations is as follows

$$
\varepsilon_{x}=\frac{\partial u}{\partial x}=\frac{1}{l_{1}^{2}}\left[\begin{array}{l}
\left(4 x-3 l_{1}\right) u_{i}+ \\
+\left(4 l_{1}-8 x\right) u_{j}+\left(4 x-l_{1}\right) u_{k}
\end{array}\right] .
$$

After a little simplification for i-quadratic finite element, the expression of the potential energy of elastic deformation (11) has the following form

$$
\begin{gathered}
\Pi_{i}=\frac{E}{2} \int_{V_{i}}\left(\frac{\partial u}{\partial x}\right)^{2} d V-\alpha E \int_{V_{i}} T(x) \frac{\partial u}{\partial x} d V= \\
=\frac{E F}{2} \int_{0}^{l_{1}} \varepsilon_{x}^{2} d x-\alpha E F \int_{0}^{l_{1}} T(x) \varepsilon_{x} d x
\end{gathered}
$$

Then, the form of the functional expressing the potential energy of the considered rod clamped at both ends will be as follows

$$
\Pi=\sum_{i=1}^{4 \kappa Э} \Pi_{i}
$$

Next we present the minimization of the total potential energy of elastic deformation of the considered rod by the nodal values of displacements

$$
\frac{\partial \Pi}{\partial u_{i}}=0, i=2,3, \ldots, n n
$$

We determine the value of the elastic displacements of the rod sections that correspond to the element nodes. After that, we propose the algorithms for computing the components of the elastic and thermal components of deformations and strains for half of each finite element [4].

$$
\left.\begin{array}{l}
\varepsilon_{x}\left(x=\frac{x_{j}-x_{i}}{2}\right)=\frac{\partial u}{\partial x}\left(x=\frac{x_{j}-x_{i}}{2}\right) ; \\
\sigma_{x}\left(x=\frac{x_{j}-x_{i}}{2}\right)=E \varepsilon_{x}\left(x=\frac{x_{j}-x_{i}}{2}\right) ; \\
\sigma_{T}\left(x=\frac{x_{j}-x_{i}}{2}\right)=-\alpha E T\left(x=\frac{x_{j}-x_{i}}{2}\right) .
\end{array}\right\}
$$

\section{The Analysis of the Effect}

After testing of the developed computational algorithm, the influence of local temperature and heat exchange on the thermal-strained and deformed state of the test rod is analyzed [5]. To do this, the values of the compressive force and the true stress on different rod parts are calculated $R,(\kappa G)$. The influence of the heat flow on the thermal strained deformed and state of the test rod was analyzed $\sigma,\left(\kappa G / c M^{2}\right)$.

The analysis of the effect of heat flow on the cross-sectional area and analyses of the effect of the heat exchange with the environment through a portion of the lateral surface on the thermal-strained and deformed state of the test rod were carried out. These results are shown in Fig. and 3-6 in Table 1.

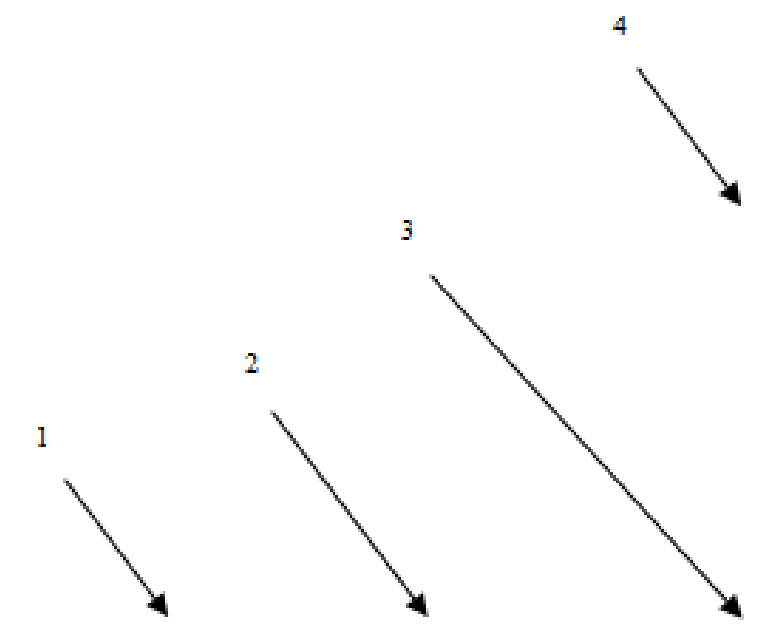

Figure 3. The field of temperature distribution along the length of the rod

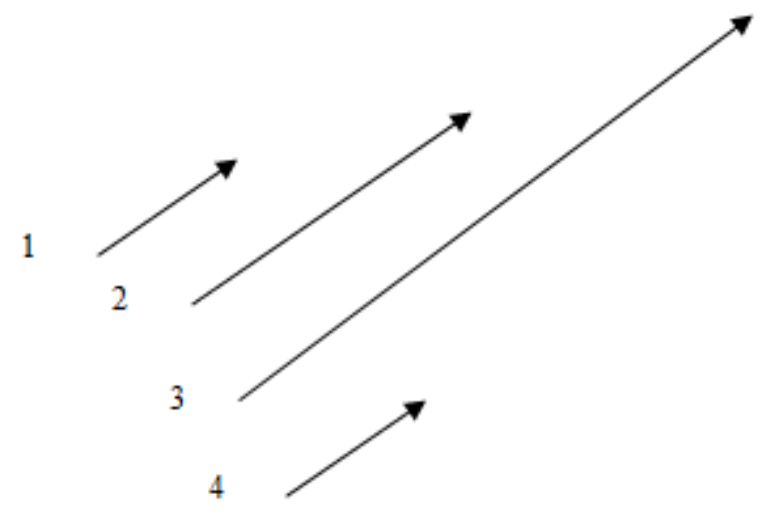

Figure 4. The law on the distribution of displacements of nodal points along the rod length 
3

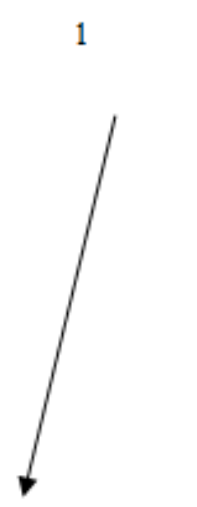

2
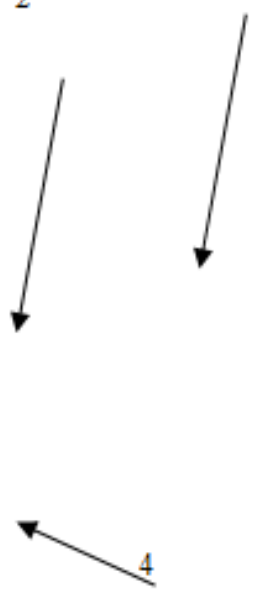

Figure 5. The field of distribution $\mathcal{E}_{x}$ of along the length of the rod

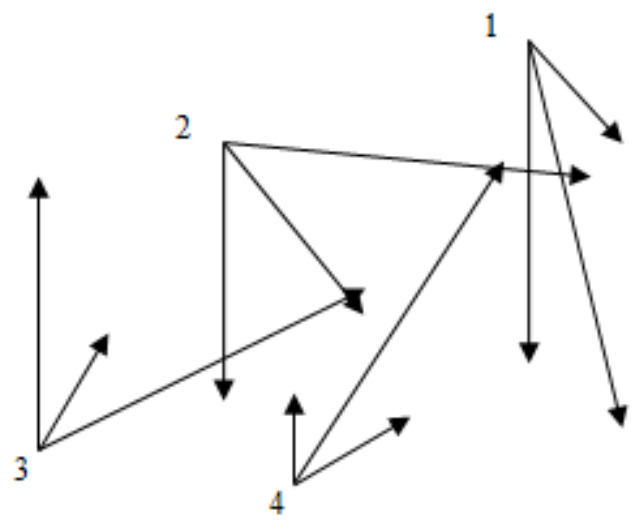

Figure 6. The field of distribution $\sigma_{x}, \sigma_{T}, \sigma$ along the length of the rod

The influence of heat flow on the thermal strained and deformed state of the test rod.

\begin{tabular}{|c|c|c|c|c|}
\hline № & Area of rod & $R,(\kappa G)$ & $\sigma,\left(\kappa G / \mathrm{cM}^{2}\right)$ & $\%$ \\
\hline 1 & $0 \leq x \leq 16(\mathrm{cM})$ & -20137 & $-1006,85$ & 100 \\
\hline 2 & $16 \leq x \leq 32(\mathrm{cM})$ & -16804 & $-840,18$ & 83,44 \\
\hline 3 & $32 \leq x \leq 48(\mathrm{cM})$ & -15693 & $-784,63$ & 77,92 \\
\hline
\end{tabular}

\section{Conclusions}

1. The corresponding calculation algorithm of the numerical investigation of efforts of the rod partially thermally insulated and clamped by two ends, in the presence of heat flow was elaborated. At the same time it was revealed that under the heat flow in the areas $0 \leq x \leq 16(c M)$, $16 \leq x \leq 32(\mathrm{~cm}) \quad, \quad 32 \leq x \leq 48(\mathrm{~cm}) \quad$,
$48 \leq x \leq 64(\mathrm{~cm})$ and $64 \leq x \leq 80(\mathrm{~cm})$ of the rod, the component values of deformations and stress components will vary accordingly $\varepsilon_{x}=100$; $138.18 ; 148.18,130.08$ and $83.81 \%, \sigma_{T}=100$; $141.64 ; 152.93,133.85$ and $84.40 \%, \sigma_{x}=100$; $138.20 ; 148.18 ; 130$ and $83.80 \%, \quad \sigma=100$; $143.53 ; 155.50,135.89$ and $84.72 \%$.

2. On the basis of the developed mathematical model, corresponding to the computational algorithm, the set of applications for solving the class of problems in order to determine the temperature distribution field, displacements, deformations, strains was developed. This complex will make it possible to calculate the lengthening value of the partially thermally insulated rod or the compressive stress and strain in the rods of limited length with the heat flow, the heat exchange, heat insulation and the axial tensile force.

\section{REFERENCES}

[1] Amirtayev K. Elongation of Partially-Thermally Insulated on the Lateral Surface of the Rod Under the Influence of Temperature, Heat Flow, Heat Transfer and Tensile Force // International Conference on Advanced Technologies, Computer Engineering and Science (ICATCES 2018), Safranbolu Turkey, 11-13 MAY, p. 241-244, 2018.

[2] Amirtayev K., Naizabayeva L., Ibadullayeva A. Development of the Complex of Software Applications to Control the State of Total Thermal Energy of an Elastic Rod // 8th IEEE International Conference on Application of Information and Communication Technologies (AICT), Astana, Kazakhstan, OCT 15-17, p. 115-119, 2014.

[3] Kudaykulov AK, Amirtayev KB, Utebaev UB. Numerical study of strain-deformed state of the rod filled-rigidly at both ends, when exposed along the length to the parabolic law of the temperature field // Materialy IV mezinarodni vedecko-prakticka conference. - Sofia, - 2008. - T.28, 21-24 p.

[4] Amirtayev KB, Utebaev UB, Tokkuliev BM, Zhumadillaeva A. Determination of the law of temperature distribution in a partially insulated tube of limited length, with the heat flow on the inner bounded surface of closed mid-pipe. // Materialy IV mezinarodni vedecko-prakticka conference - Sofia, -2008 . -66-69 p.

[5] Kudaykulov AK, Arapov BR, Kenzhegulov BZ, Amirtayev $\mathrm{KB}$, Utebaev UB, Tokkuliev BM. Numerical solution of the established thermal strained and deformed state of the heat exchanger in the presence of internal heat flow and external heat transfer of constant intensity // Materialy IV mezinarodni vedecko-prakticka conference «Veda a vznik-2008/2009». - Praha: Publishing house «Education and Science» s.r.o., - 2009. - 15-19 p.

[6] Amirtayev K.B., Ibadullaeva A.S., Akimhaze M. About one computing method of the study thermo-tense condition element to designs at presence of the sources of the heat and 
axial power // Abstracts of the third Congress of the World Mathematical Society of Turkic Countries. - Almaty, 2009. V.2, - P. 188.

[7] Kudaykulov A.K., Amirtayev K.B., Tuleuova R., Utebaev U.B., Tokkuliev B.M. Steady thermal stress-strained and deformed state of the rod in the presence of heat sources // Proceedings of the Fifth All-Russian scientific conference with international participation "Mathematical modeling and boundary value problems" - Samara - 2008. - p. 161-165.

[8] AK Kudaykulov, KB Amirtaev, UB Utebaev. Numerical study of the stressed and deformed state of the rod rigidly fixed by both ends, when the temperature field is affected by the parabolic law // Materials for the IV International Scientific Practical Conference (15-30 April 2008)
"SCIENTIFIC SPACE FOR EUROPE-2008", Volume 28 Physics Mathematics, Sofia, 2008, -21 p.

[9] AK Kudaykulov, KB Amirtaev, KI Usmanov, UB Utebaev, BMTokkuliev, RU Tuleuova. Numerical-energy method for solving 1-2 and 3-dimensional coupled problems of steady thermoelasticity // III International scientific conference "MODERN MATTERS OF MECHANICS". (Collection of abstracts), Almaty, 24-25.06.2008, 80 p.

[10] AK Kudakulov, KB Amirtaev, A.Ibaidullaeva, M.Zhunisov. Finding of prolongation of insulating rod with extensional force when two different temperatures are given on both sides // Regional scientific and methodical conference «Preparation of competitive specialists: problems, solutions»), Atyrau: Atyrau State University named after Kh.Dosmukhamedov, 2008, 161-163 p. 